\title{
Cek5, a Membrane Receptor-Type Tyrosine Kinase, Is in Neurons of the Embryonic and Postnatal Avian Brain
}

\author{
Elena B. Pasquale, ${ }^{1}$ Thomas J. Deerinck, ${ }^{2}$ S. J. Singer, ${ }^{3}$ and Mark H. Ellisman ${ }^{2}$ \\ ${ }^{1}$ La Jolla Cancer Research Foundation, La Jolla, California 92037, and 2Department of Neurosciences, San Diego \\ Microscopy and Imaging Resource, and ${ }^{3}$ Department of Biology, University of California San Diego, La Jolla, \\ California 92093
}

\begin{abstract}
Cek5 is a recently identified receptor-type tyrosine kinase of the Eph subclass that is nearly ubiquitously expressed during embryonic development (Pasquale, 1991). Cek5 is predominantly expressed in the avian CNS throughout development, and high levels remain apparent in adult neurons. By means of immunofluorescence microscopy and high-resolution immunoelectron microscopy, Cek5 was found to be expressed in many regions of the chicken brain at various developmental stages, most notably in the hippocampus and cerebellum. The highest concentration of Cek5 was observed in the molecular layer of the cerebellum, associated within the axons of mature granule cells (parallel fibers) and with the cell bodies of immature granule cells. In the axons of parallel fibers, Cek5 was concentrated in the fasiculated nonsynaptic portions. This localization, together with the "adhesion" motifs present in the Cek5 extracellular region suggest that Cek5 may interact with other cell surface-associated molecules and be involved in the growth, guidance, and/or bundling of certain unmyelinated axonal processes. Alternatively (or in addition), Cek5 may represent the receptor for a neurotrophic substance, similar to several other neuronal transmembrane tyrosine kinases.
\end{abstract}

High levels of protein tyrosine kinase expression are thought to be involved in the rapid cellular growth observed during embryonic development and in some malignancies. However, tyrosine kinases are also expressed at high levels in nonproliferating cells, such as neurons and platelets (Brugge et al., 1985; Golden et al., 1986). Among adult tissues, the brain contains the highest levels of protein tyrosine kinase activity, comparable to those found in embryonic tissues (Maher, 1991). Many different protein tyrosine kinases, including some identified very recently, have been found to be expressed in the CNS (Cotton and Brugge, 1983; Le Beau el al., 1987; Pasquale and Singer, 1989; Klein et al., 1990; Wanaka et al., 1990; Lai and Lemke, 1991; Lhotak et al., 1991; Pasquale, 1991; Sajjadi et al., 1991). Since some of these tyrosine kinases are expressed after cessation of neurogenesis, their involvement in functions other than mitogenic signal transduction is to be expected. Protein tyrosine kinases have recently been implicated in the action of neuronal

Received Jan. 23, 1992; revised Apr. 23, 1992; accepted May 8, 1992.

This work was supported by NIH Grants HD26351 to E.B.P., GM15971 to S.J.S., and NS14718, NS26739, and RR04050 to M.H.E., as well as by a Human Frontiers of Science grant to M.H.E., and a Mathers Foundation grant.

Correspondence should be addressed to Mark H. Ellisman at the above address. Copyright $(1992$ Society for Neuroscience $0270-6474 / 92 / 123956-12 \$ 05.00 / 0$ survival molecules, such as NGF (Klein et al., 1991), brainderived neurotrophic factor, neurotrophin-3 (Soppet et al., 1991; Squinto et al., 1991), fibroblast growth factors (Wagner, 1991), insulin, and insulin-like growth factor 1 (Adamo et al., 1989). Some evidence suggests that protein tyrosine kinases may also be involved in cell-cell communication and transfer of information within neural networks (Hopfield et al., 1988; Pang et al., 1988).

By screening a chicken embryo expression library with antibodies to phosphotyrosine, a novel membrane-bound tyrosine kinase receptor of the Eph family (Hirai et al., 1987), Cek5, was identified and its cDNA sequenced (Pasquale, 1991). By using polyclonal antibodies to a synthetic peptide and to a Cek5- $\beta$ galactosidase fusion protein, Cek5 was found to be developmentally regulated and predominantly expressed in chicken embryonic and adult brain. The abundant expression of Cek5 in embryonic tissues and in the adult CNS strongly suggests that its expression is important for the function of many different cell types. Here, we report the immunocytochemical localization of the Cek5 protein in the CNS, at the light microscopic and electron microscopic levels of resolution. The aim of this study is to determine precisely the cellular distribution and subcellular localization of Cek5 in specific areas of the brain in order to gain insight into the functions of this abundant receptor tyrosine kinase.

\section{Materials and Methods}

Preparation of anti-Cek5 antibodies and immunoblotting. The preparation of anti- $\beta$-galactosidase-Cek 5 fusion protein antibodies and antipeptide antibodies as well as their use in immunoblotting have been recently described in detail (Pasquale, 1991). The $\beta$-galactosidase fusion protein used as the antigen comprises amino acids 167-995 of Cek5, corresponding to most of the extracellular domain together with the entire transmembrane and catalytic domains of the protein. The antiCek 5 fusion protein antibodies were affinity purified and then absorbed on a $\beta$-galactosidase column (Pasquale, 1991). The anti-peptide antibodies were prepared by injecting the peptide QMNQIQSVEV (corresponding to the 10 carboxy-terminal amino acids of Cek5) coupled to BSA using glutaraldehyde. Specific anti-peptide antibodies were purified from the immune serum by elution with $0.1 \mathrm{M} \mathrm{HCl}$-glycine, $\mathrm{pH} 2.5$, from an immunoblot of the $\beta$-galactosidase-Cek 5 fusion protein described above.

For immunoblotting, the brain tissue extracts were prepared by sonication in ice-cold phosphate-buffered saline containing 5 mM EDTA, $1 \mathrm{~mm}$ phenylmethylsulfonyl fluoride, 0.2 trypsin inhibitor units of aprotinin $/ \mathrm{ml}, 10 \mu \mathrm{g} / \mathrm{ml}$ pepstatin, $10 \mu \mathrm{g} / \mathrm{ml}$ leupeptin, and $1 \mathrm{~mm}$ sodium orthovanadate. Tissues were frozen on dry ice immediately after dissection. Tissue homogenates were stored in aliquots at $-70^{\circ} \mathrm{C}$. The protein concentration of the tissue homogenates was estimated using a Bio-Rad protein assay (Bio-Rad Laboratories, Richmond, CA). About $200 \mu \mathrm{g}$ of protein were loaded in all the lanes. The proteins were sep- 
arated on a $7.5 \%$ polyacrylamide gel and transferred to nitrocellulose The nitrocellulose filter was stained with amido black to confirm that equal amounts of protein were present in each lane. The filter was blocked overnight with 3\% bovine serum albumin (BS $\Lambda$ ) in washing buffer $(0.1 \%$ Triton X-100 in Tris-hydroxyethyl aminoethane-buffered saline) and incubated for $2-4 \mathrm{hr}$ in washing buffer containing $3 \mu \mathrm{g} / \mathrm{ml}$ anti-Cek 5 antibodies and 3\% BSA. After thorough rinsing with washing buffer, the immunoblot was incubated for $1 \mathrm{hr}$ with ${ }^{125} \mathrm{I}$-protein $\mathrm{A}(0.25$ $\mu \mathrm{Ci} / \mathrm{ml}$; ICN, Irvine, CA) in washing buffer containing $3 \% \mathrm{BSA}$, rinsed thoroughly with washing buffer, and dried. The filter was autoradiographed at $-70^{\circ} \mathrm{C}$ overnight using Kodak (Rochester, NY) BB film and a Lightning Plus intensifying screen.

Tissue preparation for immunolocalization. Posthatching day $(\mathrm{P} 1)$ and P21 chicks were anesthetized with Nembutal and perfused transcardially with Ringer's solution followed by $4 \%$ formaldehyde in $0.1 \mathrm{M}$ phosphatebuffered saline (PBS). The entire brain was removed, bisected midsagittally, and placed in the same solution for $2 \mathrm{hr}$ at $4^{\circ} \mathrm{C}$. Embryonic day 17 (E17) cmbryos werc removed from the cgg, and the brain was excised, bisected mid-sagittally, and placed in the same fixative for 2 hr at $4^{\circ} \mathrm{C}$. For cryostat sectioning, the tissue was cryoprotected in $30 \%$ sucrose for $2 \mathrm{hr}$, embedded in OCT compound (Miles Inc.), and frozen in liquid nitrogen.

Confocal immunofluorescence microscopy. Cryostat sections, 40-50 $\mu \mathrm{m}$ thick, were cut and thawed in $1 \%$ formaldehyde in PBS and then transferred to PBS. All subsequent steps were carried out at $4^{\circ} \mathrm{C}$. The sections were treated in $0.1 \mathrm{M}$ PBS with $0.05 \mathrm{~m}$ glycine (PBS-gly) for 5 min and then blocked in $1 \%$ normal goat serum (NGS), $1 \%$ BSA, and $1 \%$ fish gelatin in PBS-gly for $30 \mathrm{~min}$, and then transferred to $0.1 \%$ NGS, $0.1 \%$ BSA, and $0.1 \%$ gelatin in PBS-gly (working buffer) for 5 $\mathrm{min}$. Sections were incubated in either rabbit anti-Cek5 $(20 \mu \mathrm{g} / \mathrm{ml})$ alone, or simultaneously with mouse anti-glial fibrillary acidic protein (GFAP) $(10 \mu \mathrm{g} / \mathrm{ml})$ or mouse anti-synaptophysin $(10 \mu \mathrm{g} / \mathrm{ml})$ for $12 \mathrm{hr}$ in working buffer. Sections were washed in working buffer for $1 \mathrm{hr}$ and then incubated for $1 \mathrm{hr}$ in either goat anti-rabbit IgG fluorescein isothiocyanate alone or together with goat anti-mouse IgG conjugated either to Texas red or lissamine rhodamine (Jackson Immunoresearch). After washing for $1 \mathrm{hr}$ in working buffer, the sections were mounted on slides in antifade media consisting of $4 \% n$-propyl gallate in $90 \%$ glycerine and PBS, pH 7.6.

Microscopy was carried out on a Zeiss Axiovert 35M instrument equipped with a Bio-Rad MRC 600 confocal laser scanning system utilizing either an argon ion or argon/krypton mixed gas laser. Images were photographed with an LFR Plus digital camera (Lasergraphics, Inc) using Kodachrome 100HC film (Kodak).

Peroxidase immunolocalization. Neonatal day 1 chick brain was fixed as described above, and 50 and $100-\mu \mathrm{m}$-thick mid-sagittal sections were prepared with a Vibratome (Lancer, Inc.). Sections were treated as described above, but after incubation with the primary antibody the sections were incubated in biotinylated goat anti-rabbit IgG (Vector Labs) for $1 \mathrm{hr}$. After $1 \mathrm{hr}$ of washes in PBS-gly, the sections were incubated in an avidin-biotin-peroxidase complex (Vector Labs) with an additional $2 \% \mathrm{NaCl}$ in PBS for $1 \mathrm{hr}$. After an additional $1 \mathrm{hr}$ of washes, the sections were reacted with $0.1 \mathrm{mg} / \mathrm{ml}$ diaminobenzidine with $1 \mu \mathrm{l} / \mathrm{ml}$ $\mathrm{H}_{2} \mathrm{O}_{2}$ in PBS for $8 \mathrm{~min}$, and then washed another $30 \mathrm{~min}$ in PBS. For light microscopy, the sections were air dried onto clean glass slides, rehydrated in double-distilled water, stabilized in $0.05 \% \mathrm{OsO}_{4}$ for 30 sec, dehydrated in an ethanol series followed by xylene, mounted in Permount, and sealed with a \#1 coverslip. For electron microscopy, the sections were postfixed in $1 \% \mathrm{OsO}_{4}$ in PBS for $1 \mathrm{hr}$ and washed in double-distilled water. Sections were then dehydrated in ethanol, infiltrated in 1:1 ethanol/Epon-Araldite for $1 \mathrm{hr}$ followed by 100\% EponAraldite for $4 \mathrm{hr}$, and polymerized between two glass slides at $60^{\circ} \mathrm{C}$.

Sections $80 \mathrm{~nm}$ and $250 \mathrm{~nm}$ thick were prepared on an Ultracut $\mathrm{E}$ (Leica), and images were recorded at $80 \mathrm{kev}$ using a JEOL $100 \mathrm{CX}$ or at $400 \mathrm{KeV}$ using a JEOL $4000 \mathrm{EX}$ electron microscope (JEOL, Inc.).

\section{Results}

Antibodies to Cek5. The anti-Cek5 antibodies used in this study were prepared by immunizing rabbits with a Cek5- $\beta$-galactosidase fusion protein produced in bacteria. These anti-Cek5 antibodies have been previously characterized and used in immunoblotting experiments to study the developmental expression and tissue distribution of Cek5 in the chicken (Pasquale,
1991). They appear to be specific for Cek5 both in immunoblotting and immunolocalization experiments. As shown in Figure $1 A$, these anti-Cek5 fusion protein antibodies do not cross-react with other proteins containing a homologous tyrosine kinase catalytic domain, such as the members of other families of tyrosine kinases. In fact, anti-Cek 5 antibodies eluted from the $120 \mathrm{kDa}$ region of an immunoblot of E10 brain recognize the $120 \mathrm{kDa}$ band in embryonic brain (lane 3), and the Cek5- $\beta$-galactosidase fusion protein (lane 2 ). However, they do not label a Cek1- $\beta$-galactosidase fusion protein (Pasquale and Singer, 1989; Cek1 amino acids 31-819) (lane 1), containing a catalytic domain, which is $35 \%$ identical at the amino acid level, to that of Cek5. Antibodies eluted as a control from the $90 \mathrm{kDa}$ region of the brain immunoblot do not significantly label the brain extract or either fusion protein (lanes 4-6).

The anti-Cek5 fusion protein antibodies produce results that are similar to those obtained with anti-Cek5 carboxy-terminal peptide antibodies, both in immunoblotting (Pasquale, 1991) and immunolocalization experiments (see Fig. 5). Thus, since the 10 carboxy-terminal amino acids of the members of the Eph family are not well conserved, the labeling obtained with the anti-fusion protein antibodies is specific and cannot be attributed to cross-reactivity with other members of the Eph family. Because the anti-fusion protein antibodies produced stronger labeling, they were used for most experiments.

Immunoblotting. The abundance of Cek 5 was examined by immunoblotting extracts of the cerebrum and cerebellum separately. As shown in Figure $1 B$, the anti-Cek5 antibodies labeled a single band of $\sim 120 \mathrm{kDa}$ in embryonic, neonatal, and adult chicken cerebrum and cerebellum. Cek5 was found to be expressed at overall comparable levels in these two regions of the brain (Fig. $1 B$ ). The expression of Cek5 in the cerebrum decreased gradually during embryonic development as well as after hatching (Fig. 1 $B$, lanes 1-5). In the cerebellum, the decrease in Cek5 expression was less pronounced than in the cerebrum, particularly between days E12 and P21 (Fig. 1B, lanes 6-10).

Overall distribution of Cek5 in brain. In order to examine the overall spatial distribution of Cek5 in the chicken brain, 50$\mu \mathrm{m}$-thick mid-sagittal sections of whole chick brain at $\mathrm{P} 1$ were immunolabeled using a peroxidase-based detection method (Fig. $2 A$ ). This stage of development (P1) was chosen because it is intermediate between embryonic and adult and because the different regions of the brain are well defined. Cek5 immunoreactivity was found to be widely, but not uniformly, distributed throughout the neonatal chick brain. The most prominent immunoreactivity was detected in the cerebellum, particularly in the molecular layer and the external germinal layer. The granule cell layer of the cerebellum, however, was only weakly stained. Outside the cerebellum, the hippocampus and area hippocampus were also prominently stained. Moderate immunoreactivity was observed in the neostriatum, hypothalamus, and dorsal thalamus along with the reticular formation. The central white matter of the hatchling cerebellum was the most notable region of the CNS appearing devoid of Cek5 expression. Nonimmune rabbit serum used as a control produced essentially no staining (Fig. 2C), and preincubation of the anti-Cek5 antibodies with Cek5- $\beta$-galactosidase fusion protein virtually abolished labeling in all regions of the brain (Fig. $2 B$ ). Immune, but not preimmune, serum containing antibodies directed to the Cek5 carboxy-terminal peptide (Pasquale, 1991) also produced prominent staining of the molecular layer of the cerebellum (not shown), further confirming the specificity of the anti-Cek $5-\beta$-galactosi- 


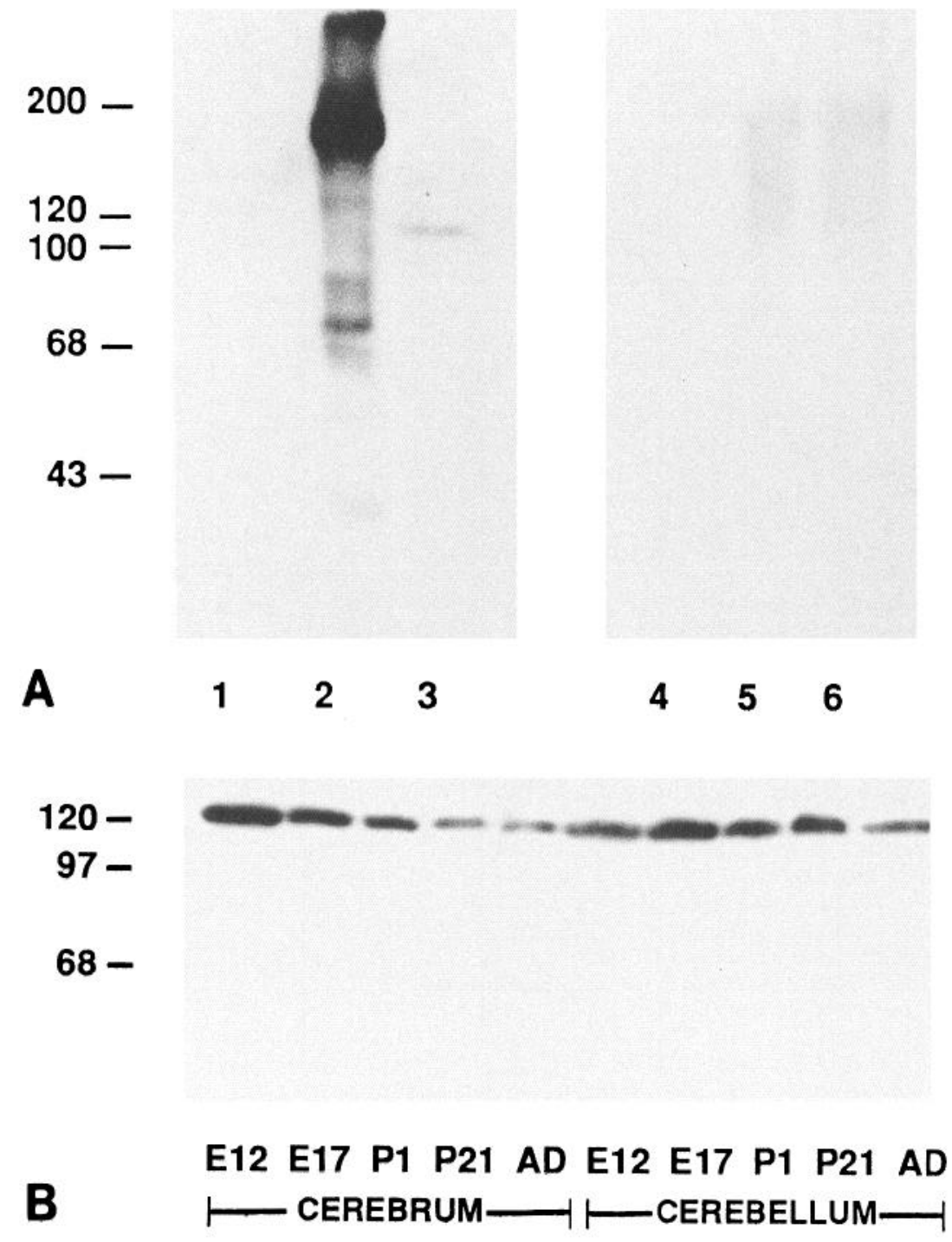

dase fusion protein antibodies (see also Fig. 5). Views at higher magnification of the cerebellum (Fig. $3 \mathrm{~A}$ ) and the hippocampus (Fig. $3 B$ ), the two areas of the brain displaying the most prominent immunoreactivity, confirmed that in the cerebellum Cek5 is primarily expressed in the molecular layer and in the external germinal layer, and in the hippocampus in the areas surrounding the cell bodies. The staining in both of these areas is abolished by preincubation of the antibodies with the $\beta$-galactosidaseCek5 fusion protein (Fig. $3 C, D$ ). These results indicated that Cek 5 expression is particularly high in regions rich in nerve cell processes. Interestingly, the distribution of Cek5 in the cerebellum is reminiscent of that of several adhesion molecules involved in the formation of cerebellar cortical layers (Chuong et al., 1987).

Distribution of Cek5 in the cerebellum. The cerebellum was chosen for further investigation since both the Cek 5 greatest and least immunoreactivity were observed in this region (Fig. 2A). In addition, the developmental processes involved in the formation of the cerebellum have been extensively characterized (Ramon y Cajal, 1890; Hanaway, 1967; Feirabend et al., 1976; Feirabend, 1990). The cerebellum contains well-defined layers with distinct cellular compositions. The molecular layer of the cerebellum is mostly composed of the axons of granule cells, or parallel fibers, and is formed when postmitotic granule cells migrate from the external germinal layer to the internal granular layer. This causes the axons and the cell bodies of granule neurons to be localized in different regions of the cerebellum. At $\mathrm{E} 17$, the external germinal layer, which is prominent due to the intense proliferation of granule cells, was heavily stained by the anti-Cek5 antibodies (Fig. 4A). The developing molecular layer at E17, which is not as well organized as at P1, was intensely labeled with anti-Cek5 antibodies (Fig. 4A). Compared to E17, Cek5 immunoreactivity was similarly distributed in the neonatal chicken brain but was somewhat less intense (Fig. 4B). At P21, intense staining was restricted to the residual external germinal layer (Fig. $4 C$ ), which in the chicken persists until adulthood. At P21, Cek5 immunoreactivity was still detectable in the molecular layer, but only faintly. The Cek5 immunoreactivity of the postmigratory granule cell bodies (internal granular layer) was consistently very low between E17 and P21. Thus, the decrease in Cek5 abundance during development is not uniform in all portions of the granule cells. No reactivity was observed in the Purkinje cell bodies, in either their dendrites or axons, or in stellate cells. As a further control for the specificity 


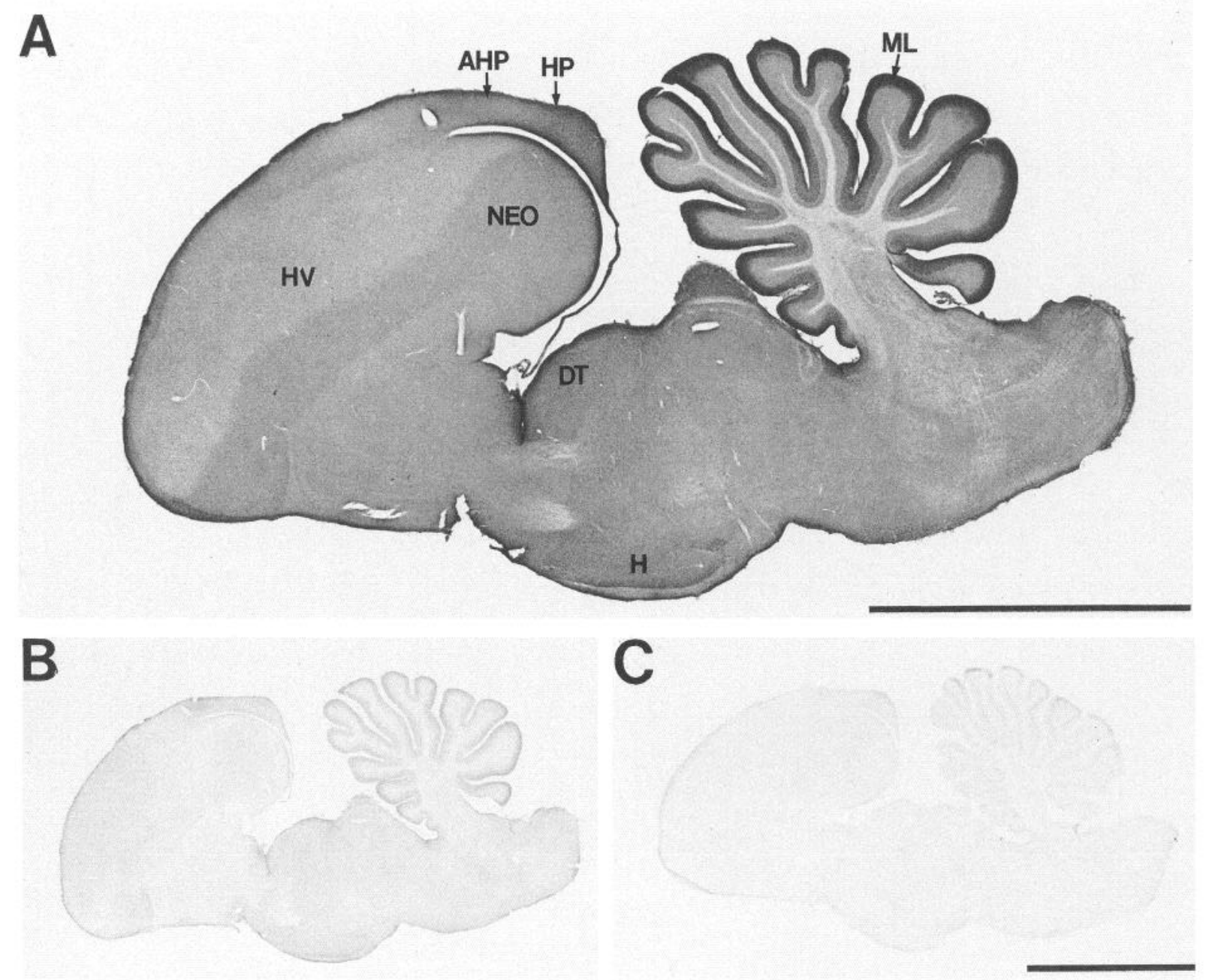

Figure 2. Peroxidase immunolocalization of Cek5 in P1 chicken brain using anti-fusion protein antibodies. $A$, Sagittal section of the whole brain is shown. $M L$, molecular layer of the cerebellum; $H P$, hippocampus; $A H P$, area parahippocampus; $N E O$, neostriatum; $D T$, dorsal thalamus; $H$, hypothalamus; $H V$, hyperstriatum ventrale. $B$, Section serial to $A$ with anti-fusion protein antibodies blocked with the $\beta$-galactosidase-Cek 5 fusion protein. $C$, Section serial to $A$, with nonimmune rabbit serum in place of anti-Cek5 antibodies. Scale bars, $5 \mathrm{~mm}$.

of the anti-fusion protein antibodies, different polyclonal antibodies (directed to the Cek5 C-terminal 10 amino acids) were used to probe chicken cerebellum at P1. By comparing Figure 5 with Figures $4 B$ and $6 A$, it is clear that the two different antiCek5 antibodies produce similar staining patterns.

The Bergmann glia represent another prominent component of the cerebellar molecular layer. Double labeling with anti-Cek 5 (Fig. 6A) and anti-GFAP (Fig. 6B) antibodies (which were used to label the Bergmann glia) showed that Cek5 was not associated with these astrocytes; complementary regions are stained with the two antibodies. This further suggests that Cek5 is specifically expressed in neurons. The molecular layer of the cerebellum is also very rich in synaptic connections, particularly between the granule cell axons and the dendrites of Purkinje cells. Similar to Cek5 immunoreactivity, synaptophysin immunoreactivity (marking synaptic vesicles) is concentrated in the molecular layer of the cerebellum. However, high-resolution confocal microscopy with doubly labeled sections demonstrated that the labeling of Cek5 (Fig. 6C) and synaptophysin (Fig. 6D) did not coincide. Furthermore, unlike the staining with anti-Cek 5 antibodies, synaptophysin immunoreactivity was prominent around the Purkinje cell bodies and absent from the external germinal layer (not shown).

The ultrastructural distribution of Cek5 was determined by immunoelectron microscopy (Fig. 7). Cek5 immunoreactivity was clearly concentrated in parallel fibers, with the exception of the enlargements of parallel fibers corresponding to synapses onto Purkinje cells. As expected from the low-resolution studies, Cek5 was not detected in the Purkinje cell dendrites, which are also present in the molecular layer of the cerebellum, nor on the pial surface. As shown in Figure 7, Cek5 immunoreactivity was observed throughout the cross sections of parallel fibers. Because parallel fibers are very small in diameter $(\sim 0.2 \mu \mathrm{m})$, this apparently diffuse distribution could be attributed to any of several different causes. For example, the products of the peroxidase enzymatic reaction may diffuse throughout the parallel fibers interiors, especially if the antibodies were primarily directed to cytoplasmic epitopes. More likely, however, is that Cek 5 could be present not only on the plasma membrane, but also on intracellular membrane systems involved in the intracellular traffic to the plasma membrane. The amino acid sequence of Cek5, its association with membrane-containing sub- 

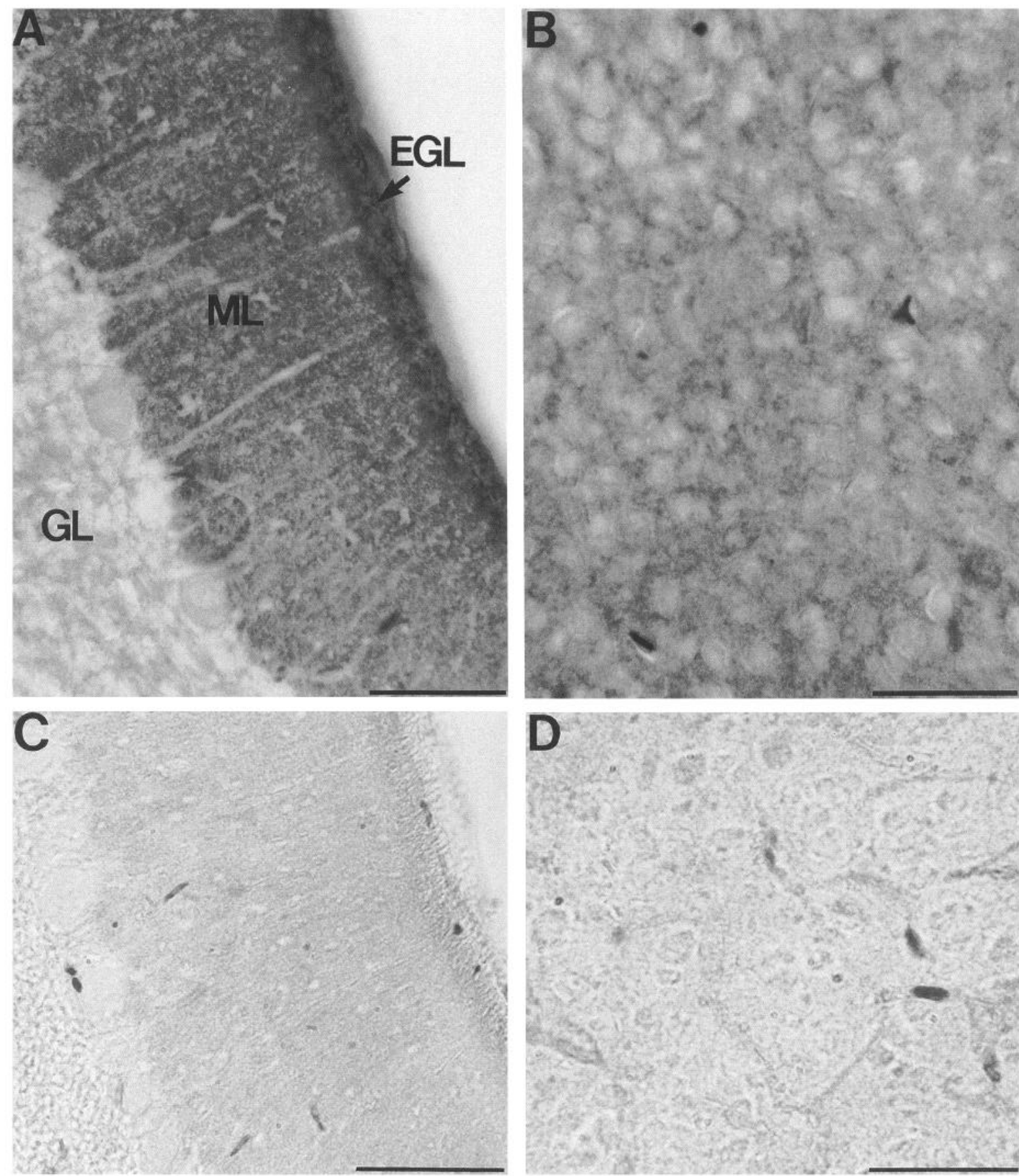

Figure 3. Immunolocalization of Cek 5 in the chicken cerebellum and hippocampus at $\mathrm{P} 1$ using anti-fusion protein antibodies. $A$, In the cerebellum, most of the immunoreactivity is found in the external germinal layer $(E G L)$ and the molecular layer. The granule cell layer $(G L)$ exhibits very weak immunoreactivity. $B$, In the hippocampus, Cek 5 immunoreactivity is found mostly outside of neuronal cell bodies. Controls for $A$ and $B$, using antibodies blocked with the $\beta$-galactosidase-Cek5 fusion protein, are shown in $C$ and $D$, respectively. Scale bars, $50 \mu \mathrm{m}$.

cellular fractions (Pasquale, 1991), and its glycosylation (E. B. Pasquale, unpublished observations) indicate that Cek5 is indeed an integral membrane protein.

The presence of Cek5 in the cell bodies of granule cells both in the internal granular layer (Fig. $8 A$ ) and in external germinal layer (Fig. $8 B$ ) was also confirmed by electron microscopy.

\section{Discussion}

It is becoming increasingly clear that neuronal survival molecules utilize signaling pathways very similar to those activated by mitogenic growth factors. This was first suggested by the finding that treatment of cultured PC12 cells with NGF causes a substantial and rapid increase in protein tyrosine phosphorylation (Maher, 1988). In fact, as was recently shown, the cell surface high-affinity receptor for NGF is the integral membrane tyrosine kinase Trk (Kaplan et al., 1991; Klein et al., 1991). However, in neurons the final result of the activation of receptor tyrosine kinases is normally not cell proliferation. Rather, tyrosine kinases appear to be important for the differentiation and maintenance of cells with neuronal phenotypes. Neuronal ty- 

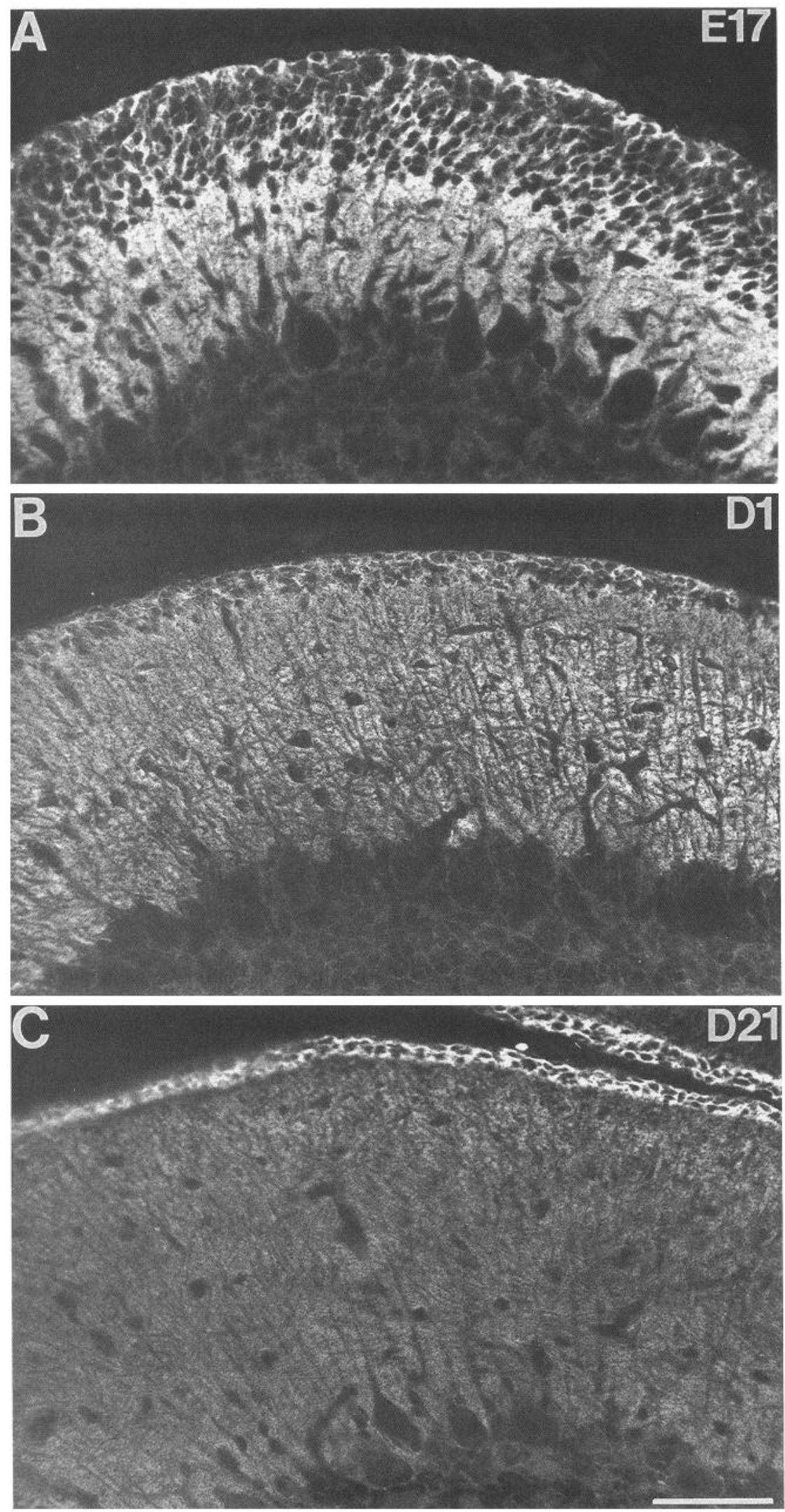

Figure 4. Confocal laser scanning immunofluorescence images of the distribution of Cek5 in the chicken cerebellum during development using antifusion protein antibodies. $A$, E17. $B$, P1. $C, \mathrm{P} 21$. The expression of Cek 5 in the molecular layer decreases during development, while it remains high in the external germinal cell layer. Scale bar, $50 \mu \mathrm{m}$. rosine kinases could be essential both during the ontogeny of the nervous system, when the limited availability of survival molecules causes the differentiation and maintenance of only selected nerve cells, and during adulthood, for the survival of terminally differentiated neurons. Interestingly, in spite of the high tyrosine kinase activity and high levels of expression of tyrosine kinases in adult brain, the overall steady state levels of protein tyrosine phosphorylation are very low (Maher and Pas- 


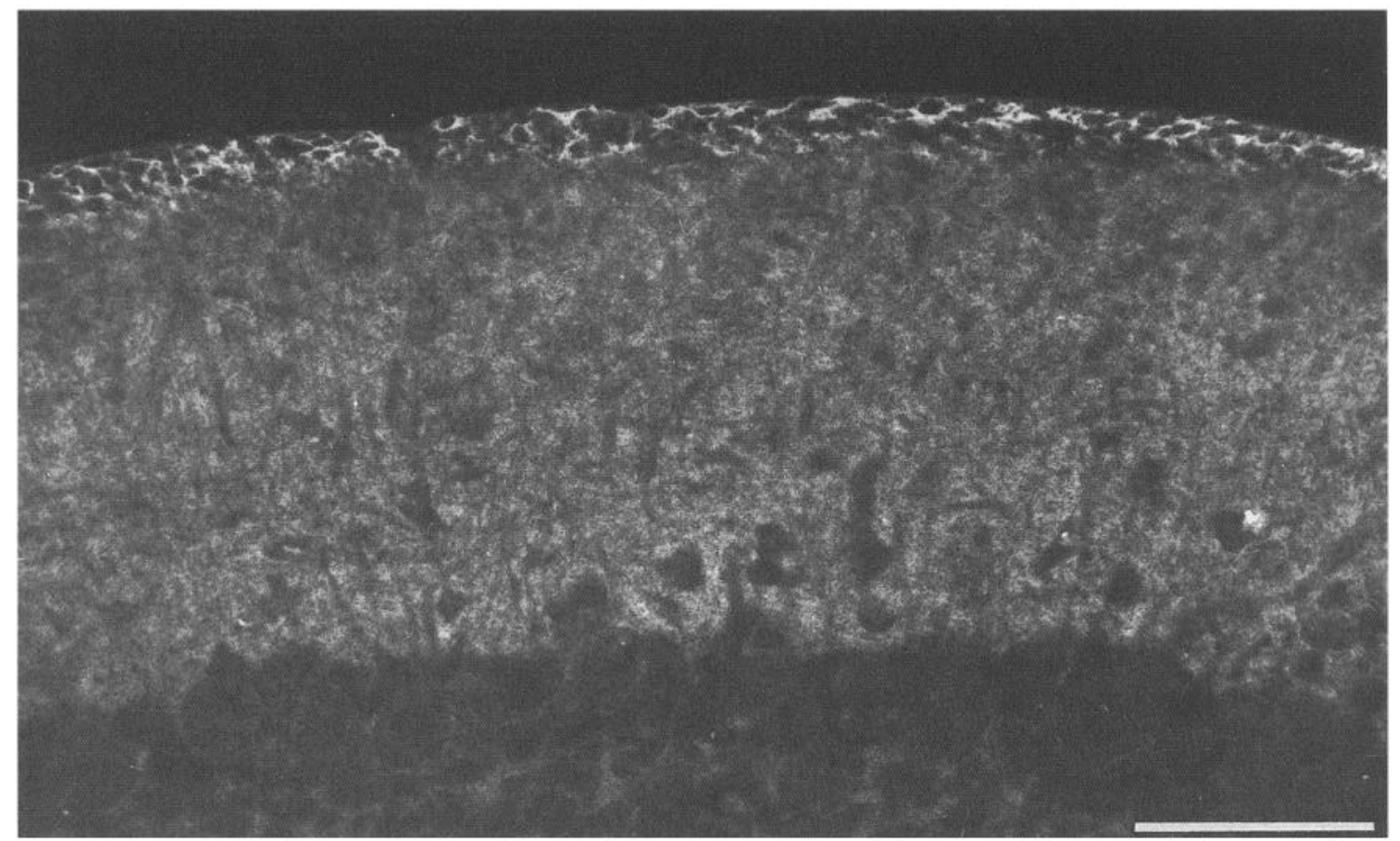

Figure 5. Confocal laser scanning immunofluorescence images of the distribution of Cek5 in the chicken cerebellum at P1 using antibodies to the $\mathrm{C}$-terminal synthetic peptide. Staining with these antibodies produces results that are similar to those obtained with anti-Cek5 fusion protein antibodies (compare with figs. $4 B, 6 A$ ). Staining with these anti-peptide antibodies confirmed that the Cek5 immunoreactivity is restricted to the molecular layer and the external granule cell layer. Since staining with this anti-peptide antibody is significantly weaker than the equally specific anti-fusion protein antibody, the principal observations of this work are illustrated with the latter.

quale, 1988). Thus, tyrosine kinase activity in the adult CNS must be tightly regulated, for example by the activity of phosphotyrosine phosphatases and, presumably, of specific inhibitors (Maher, 1991; Tian et al., 1991; Yang et al., 1991).

Cek5 belongs to the Eph family (Hirai et al., 1987), one of the least characterized families of receptor-type tyrosine kinases. Several members of this family of receptor tyrosine kinases have been identified recently and completely sequenced (Lindberg and Hunter, 1990; Lhotak et al., 1991; Sajjadi et al., 1991), and many more are known to exist (Chan and Watt, 1991; Lai and Lemke, 1991; Pasquale, unpublished observations). The known members of the Eph family share conserved cysteine residues, an immunoglobulin-like domain (O'Bryan et al., 1991), and two repeats similar to fibronectin type III repeats in the extracellular domain (Pasquale, 1991; Sajjadi et al., 1991). Thus, the extracellular domains of Cek5 and of the other Eph-related kinases have features similar to those of molecules involved in proteinprotein interactions at the cell surface, including neural cell adhesion molecules (Norton et al., 1990; Pasquale, 1991). The ligands and the substrates interacting with the members of the Eph family have not yet been identified.

Cek 5 was previously found to be expressed at high levels in many tissues throughout development and in the adult brain (Pasquale, 1991). In this report, we have shown that Cek5 is concentrated in areas of the chicken CNS that are rich in neuronal processes and fasciculating axons, most notably in the hippocampus and in the cerebellum. In the cerebellum, Cek5 immunoreactivity is present in proliferating as well as in postmitotic neurons. The highest concentration of Cek5 was observed in the molecular layer of the cerebellum, associated with the axons of mature granule cells (parallel fibers) and with the cell bodies of immature granule cells (before migration to the granular layer). Although the molecular layer of the cerebellum is particularly rich in synapses, Cek 5 appears to be concentrated in the intersynaptic portions of the parallel fiber axons. This distribution of Cek5, together with the recent findings that a number of neurotrophic substances act through tyrosine kinase receptors, suggests that Cek 5 may be implicated in neuronal survival and differentiated functions. Furthermore, both the presence of repeats homologous to immunoglobulin and fibronectin type III repeats in the extracellular domain of Cek5 and its distribution suggest a role in the regulation of the growth of parallel fibers and/or of their associations with neighboring cells. Remarkably, several neuronal adhesion molecules that are expressed in cerebellar granule cells and concentrated in the molecular layer (Chuong et al., 1987) also contain immunoglobulin and fibronectin type III motifs in their extracellular domains (Moos et al., 1988; Norton et al., 1990).

Further suggesting a role for tyrosine phosphorylation in axonal outgrowth and adhesion, three receptor-like tyrosine phosphatases containing multiple fibronectin type III motifs have recently been shown to be selectively expressed in CNS axons of the Drosophila embryo (Tian et al., 1991; Yang et al., 1991). Homotypic or heterotypic interactions among the extracellular domains of neuronal tyrosine kinases and phosphatases and neuroadhesion molecules may play a role in linking cell adhesion and signal transduction cascades.

The detailed knowledge of the spatial distribution of Cek5 in embryonic and adult tissues may be helpful in the identification of the Cek5 ligand. This ligand is expected to be highly expressed in the CNS, where it may act as a neurotrophic factor and/or represent a molecule associated with the surface of neighboring cells. Furthermore, the Cek5 ligand is expected to be present not only in the embryonic and adult CNS, but also in the other 

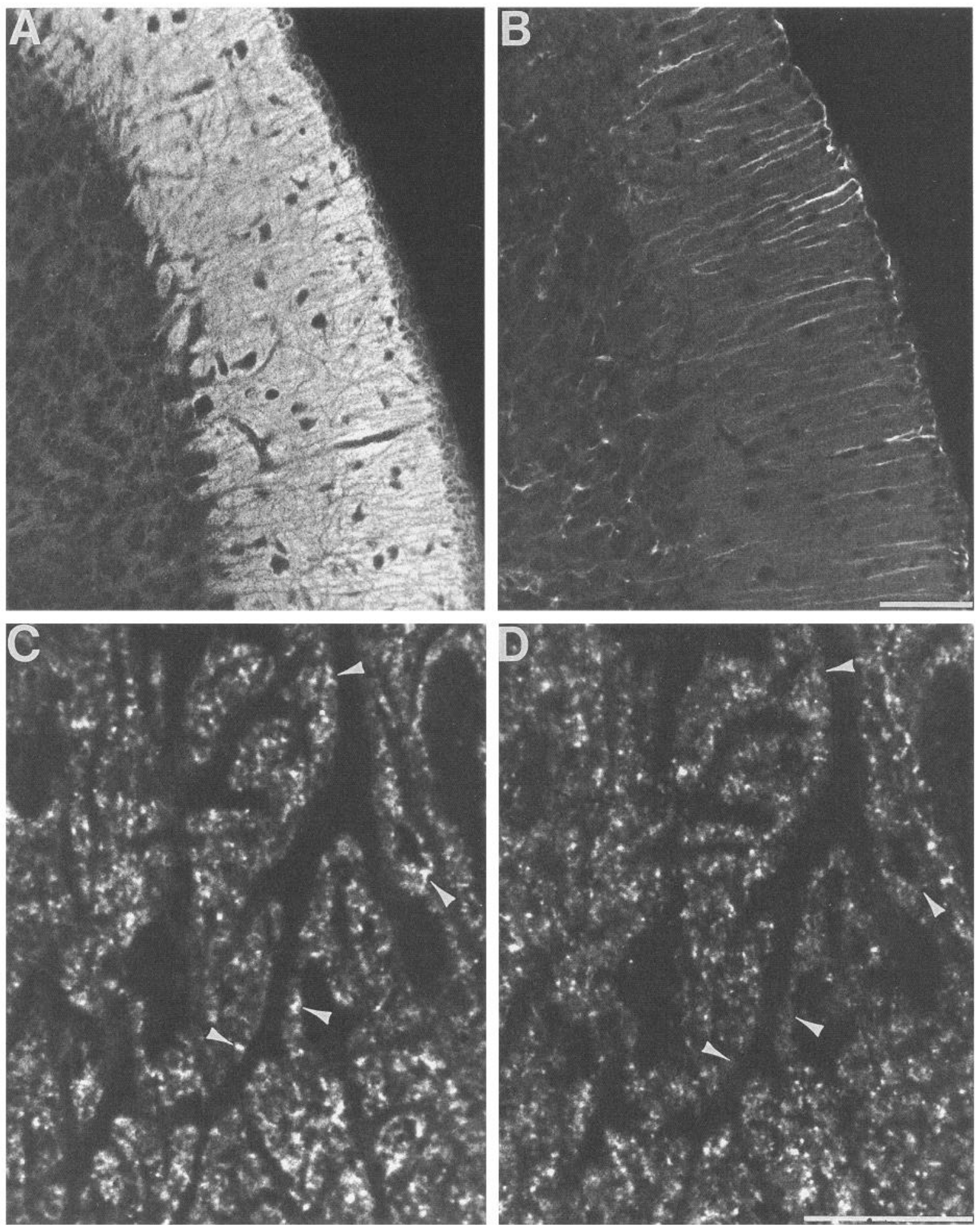

Figure 6. Comparison of the immunofluorescent microscopic localization of Cek5, GFAP, and synaptophysin in P1 chicken cerebellum using by confocal microscopy. $A$ and $B$, Simultaneous localization by double labeling of Cek5 $(A)$ (using anti-fusion protein antibodies), and of GFAP $(B)$ marking glia, demonstrates that the distributions of the two proteins are not overlapping. $C$ and $D$, Simultaneous high-resolution localization by double immunofluorescent labeling of Cek5 $(C)$ and synaptophysin $(D)$ in the molecular layer of the cerebellum. Arrowherds indicate prominent regions of Cek5 immunoreactivity that do not coincide with that of synaptophysin. Scale bars: $B, 50 \mu \mathrm{m}$ for $A$ and $B ; D, 10 \mu \mathrm{m}$ for $C$ and $D$.

tissues expressing Cek5. This wide tissue distribution would resemble that of several known growth factors, such as fibroblast growth factor, insulin, and insulin-like growth factor 1 . These growth factors represent differentiation and survival factors for neuronal cells (Adamo et al., 1989; Wagner, 1991; Walicke et al., 1986) but are also expressed in tissues other than the brain and are mitogenically active on cell types other than neurons.

Receptor-type tyrosine kinases other than Cek5 are also ex- 

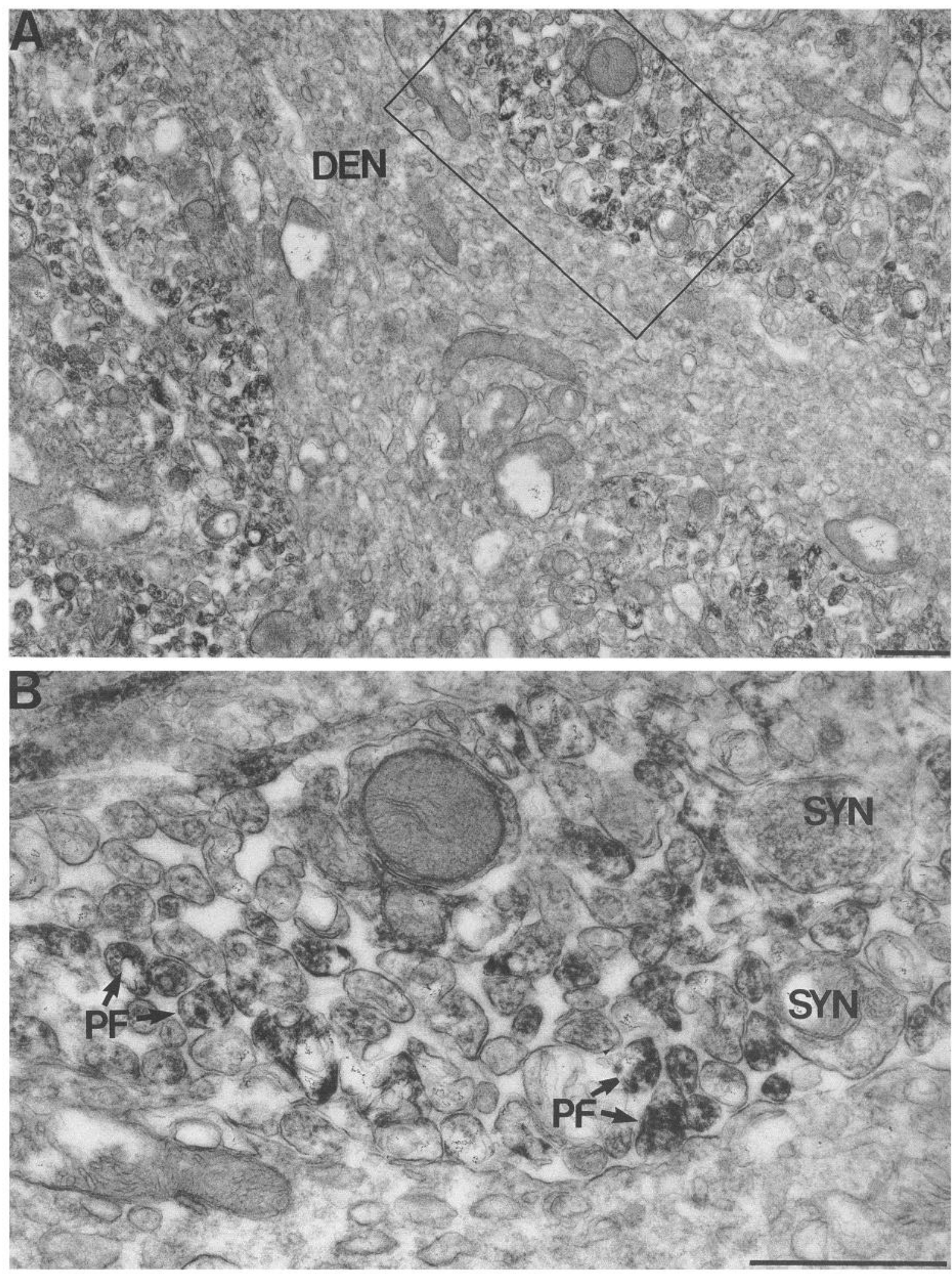

Figure 7. Electron microscopic immunolocalization of Cek5 in the molecular layer of the P1 chicken cerebellum. In $A$, a Purkinje cell dendrite $(D E N)$ is shown, devoid of labeling and surrounded by parallel fibers (granule cell axons) shown in cross section and heavily labeled. The boxed area in $A$ is shown enlarged in $B$. SYN, synapse; $P F$, parallel fibers. Scale bars, $1 \mu \mathrm{m}$. 

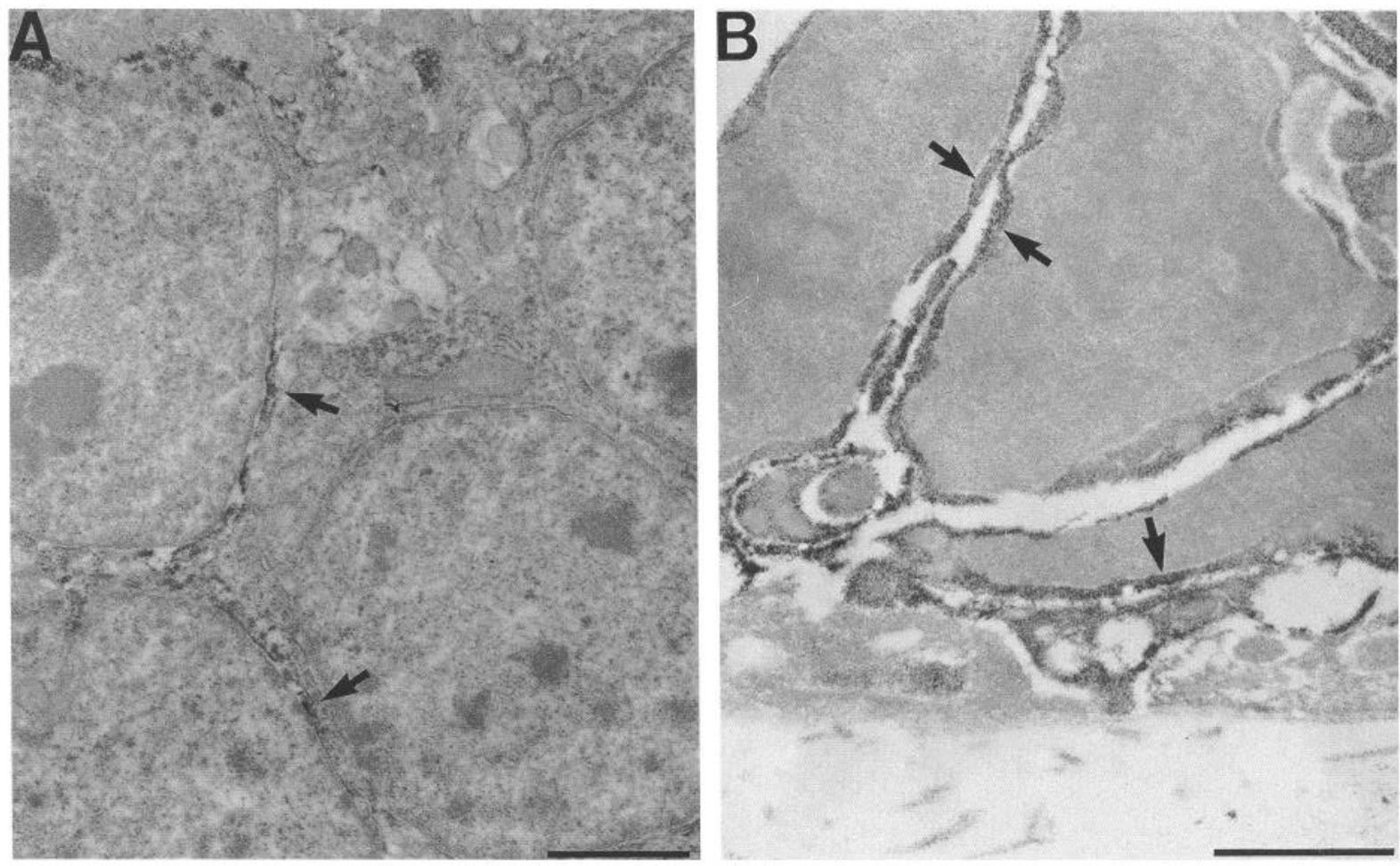

Figure 8. Electron microscopic immunolocalization of Cek5 in the cell bodies of granule cells in P1 chicken cerebellum. $A$, In the postmigratory granule cell layer, immunoreactivity is very weak (arrows) and infrequent. $B$, In premigratory granule cells of the external germinal layer, labeling of the thin layer of cytoplasm and plasma membrane surrounding the prominent nuclei of immature granule cells is uniform and intense. Scale bars, $2 \mu \mathrm{m}$.

pressed in the adult CNS. These include other members of the Eph family (Chan and Watt, 1991; Lai and Lemke, 1991; Lhotak et al., 1991; Sajjadi et al., 1991), several fibroblast growth factor receptors (Pasquale and Singer, 1989; Wanaka et al., 1990; Lai and Lemke, 1991), the insulin and insulin-like growth factor 1 receptors (Adamo et al., 1989; Moss et al., 1990), and the brainderived neurotrophic factor receptor TrkB (Klein et al., 1990, 1991). The presence in brain of platelet-derived growth factor receptors has also been suggested based on the expression of platelet-derived growth factors A and B (Sasahara et al., 1991; Yeh et al., 1991).

This study represents the first demonstration of the selective localization of a receptor-type tyrosine kinase to the axons of neuronal cells in the CNS. Where the spatial distribution of receptor tyrosine kinases in the CNS has been investigated, it has mostly been at the mRNA level at low resolution. The presence of mRNA allows the identification of the types of cells expressing a specific tyrosine kinase gene but does not necessarily imply that the kinase itself is expressed. Furthermore, the subcellular distribution of these kinases cannot be inferred from the study of their mRNAs. Because dendrites and axons often extend considerable distances away from their cell bodies, the precise subcellular distribution of neuronal proteins can provide important clues as to their functions.

Typically, receptor tyrosine kinase genes are expressed in at least several regions of the brain. Similar to Cek5, many appear to be especially abundant in the hippocampus and in the cerebellum (Moss et al., 1990; Wanaka et al., 1990; Lai and Lemke, 1991). mRNAs encoding receptor tyrosine kinases different from Cek 5 have been detected in the granule cells of the cerebellum. These include a fibroblast growth factor receptor (FGFR-1)
(Wanaka et al., 1990), TrkC (Lambelle et al., 1991), and Tyro3 (Lai and Lemke, 1991). These kinases may act in concert with Cek5 (especially if they are found to be expressed predominantly in the parallel fibers), or they may have complementary functions to those of Cek5 in granule cells. Other receptor tyrosine kinases are present in the cerebellum, but in different cell types. For example, TrkB (Klein et al., 1990) and Tyro6 (Lai and Lemke, 1991) are concentrated in Purkinje cells; Tyrol (Lai and Lemke, 1991) is localized to the Purkinje cell layer, the inferior olive, and the lateral nucleus of the cerebellum; and FGFR-2 or Bek, which is a fibroblast growth factor receptor, is expressed in non-neuronal cells in the white matter glia of the cerebellum (Lai and Lemke, 1991).

The 57 amino acids of the rat Tyro5 catalytic domain that have been recently sequenced by Lai and Lemke (1991) are identical to the corresponding amino acids of chicken Cek5. However, the distribution of the Tyro5 mRNA, which is expressed at high level in adult rat cerebellar Purkinje cells, does not correspond to the distribution of the Cek 5 protein in chicken cerebellum. Whether this can be attributed to the different ages of the animals examined, to species differences, to the fact that the abundance of mRNA does not correlate with the abundance of the corresponding protein, or to the fact that Cek5 and Tyro5 may be closely related but different genes, is not known.

Like the integral membrane tyrosine kinases described above, many cytoplasmic tyrosine kinases (which lack extracellular and transmembrane regions) are abundantly expressed in the CNS. These tyrosine kinases, which are localized in intracellular compartments, are thought in many cases to interact with the phosphorylated cytoplasmic portions of activated receptor tyrosine kinases and to amplify their signals (Koch et al., 1991). The 
best-studied cytoplasmic tyrosine kinase is p60c-src, which is expressed at high levels in neurons (Brugge et al., 1985). Interestingly, the distribution of p60 ${ }^{\mathrm{c}-\mathrm{src}}$ in the cerebellum is similar to that of Cek5, since p60 ${ }^{\mathrm{c}-\mathrm{src}}$ was found to be concentrated in the molecular layer of the developing chicken cerebellum, where it appears to be mostly confined to neuronal processes (Fults et al., 1985; Sudol et al., 1988). In contrast, p60 ${ }^{\text {c-yes }}$, which is closely related to $\mathrm{p} 60^{\mathrm{c}-\mathrm{src}}$, is concentrated in cerebellar Purkinje cell bodies and dendrites (Sudol et al., 1989). Another cytoplasmic tyrosine kinase, $c-a b l$, also appears to be concentrated in the axons of neuronal cells and to be important for the formation and maintenance of axonal structures in Drosophila (Gertler et al., 1989).

The localization of many protein tyrosine kinases to neuronal processes is consistent with the concentration of phosphotyrosine immunoreactivity in axonal processes observed in the developing cerebellum (Tillotson and Wood, 1989). Activation of receptor tyrosine kinases could lead, directly or indirectly, to the phosphorylation on tyrosine of structural proteins within axons, such as tubulin, which can be phosphorylated on tyrosine by p60 ${ }^{\mathrm{c}-\mathrm{src}}$ (Matten et al., 1990), and the microtubule-associated protein tau (Kadowaki et al., 1985). Phosphorylation of these proteins on tyrosine may modulate the assembly of microtubules (Wandosell et al., 1987), affecting the formation and growth of axonal processes or the transport of molecules or vesicles along axons. While it is tempting to speculate regarding possible targets and ligands for the new tyrosine kinase receptor Cek5, elucidation of these aspects of its function will require further study.

\section{References}

Adamo M, Raizada MK, LeRoith D (1989) Insulin and insulin-like growth factor receptors in the nervous system. Mol Neurobiol 3:71100.

Brugge IS, Cotton PC, Queral AE, Barrett JN, Nonner D, Keane RW (1985) Neurones express high levels of a structurally modified, activated form of pp60c-src. Nature 316:554-557.

Chan J, Watt VM (1991) eck and erk, new members of the eph subclass of receptor protein-tyrosine kinases. Oncogene 6:1057-1061.

Chuong C-M, Crossin KL, Edelman GM (1987) Sequential expression and differential function of multiple adhesion molecules during the formation of cerebellar cortical layers. J Cell Biol 104:331-342.

Cotton PC, Brugge JS (1983) Neural tissues express high levels of the cellular src gene product p60 ${ }^{\mathrm{c}-\mathrm{src}}$. Mol Cell Biol 3:1157-1162.

Feirabend HK (1990) Development of longitudinal patterns in the cerebellum of the chicken (Gallus domesticus): a cytoarchitectural study on the genesis of cerebellar modules. Eur J Morphol 28:169223.

Feirabend HKP, Vielvoye GJ, Freedman SL, Voogd J (1976) Longitudinal organization of afferent and efferent connections of the cerebellar cortex of White Leghorn (Gallus domesticus). Exp Brain Res [Suppl] I:71-78.

Fults DW, Towle AC, Lauder JM, Maness PF (1985) pp60 ${ }^{\mathrm{r}-\mathrm{src}}$ in the developing cerebellum. Mol Cell Biol 5:27-32.

Gertler FB, Bennet RL, Clark MJ, Hoffmann FM (1989) Drosophila abl tyrosine kinase in embryonic CNS axons: a role in axonogenesis is revealed through dosage-sensitive interactions with disabled. Cell 58:103-113.

Golden A, Nemeth SP, Brugge JS (1986) Blood platelets express high levels of the pp60 6 -src specific tyrosine kinase activity. Proc Natl Acad Sci USA 83:852-856.

Hanaway J (1967) Formation and differentiation of the external granular layer of the chick cerebellum. J Comp Neurol 131:1-14.

Hirai H, Maru Y, Hagiwara K, Nishida J, Takaku F (1987) A novel putative tyrosine kinase receptor encoded by the eph gene. Science 238:1717-1720.

Hopfield JF, Tank DW, Greengard P, Huganir RL (1988) Functional modulation of the nicotinic acetylcholine receptor by tyrosine phosphorylation. Nature 336:677-680.

Kadowaki T, Fujita-Yamaguchi Y, Nishida E, Takaku F, Akiyama T, Kathuria S, Akanuma Y, Kasuga M (1985) Phosphorylation of tubulin and microtubule-associated proteins by the purified insulin receptor kinase. J Biol Chem 260:4016-4020.

Kaplan DR, Martin-Zanca D, Parada LF (1991) Tyrosine phosphorylation and tyrosine kinase activity of the $t r k$ proto-oncogene product induced by NGF. Nature 350:158-160.

Klein R, Martin-Zanca D, Barbacid M, Parada LF (1990) Expression of the tyrosine kinase receptor gene trkB is confined to the murine embryonic and adult nervous system. Development 109:845-850.

Klein R, Jing S, Nanduri V, O'Rourke E, Barbacid M (1991) The trk proto-oncogene encodes a receptor for nerve growth factor. Cell 65 : 189-197.

Koch CA, Anderson D, Moran MF, Ellis C, Pawson T (1991) SH2 and SH3 domains: elements that control interactions of cytoplasmic signaling proteins. Science 252:668-674.

Lai C, Lemke G (1991) An extended family of protein-tyrosine kinase genes differentially expressed in the vertebrate nervous system. Neuron 6:691-704.

Lambelle F, Klein R, Barbacid M (1991) trkC, a new member of the trk family of tyrosine protein kinases, is a receptor for neurotrophin3. Cell 66:967-979.

Le Beau JM, Wiestler OD, Walter G (1987) An altered form of pp60 ${ }^{\text {c-src }}$ is expressed primarily in the central nervous system. Mol Cell Biol 7:4115-4117.

Lhotak V, Greer P, Letwin K, Pawson T (1991) Characterization of Elk, a brain-specific receptor tyrosine kinase. Mol Cell Biol 11:24962502.

Lindberg RA, Hunter T (1990) cDNA cloning and characterization of ECK, an epithelial cell receptor protein-tyrosine kinase in the cph $\mid \mathrm{clk}$ family of protein kinases. Mol Cell Biol 10:6316-6324.

Maher PA (1988) Nerve growth factor induces protein-tyrosine phosphorylation. Proc Natl Acad Sci USA 85:6788-6791.

Maher PA (1991) Tissue-dependent regulation of protein tyrosine kinase activity during embryonic development. J Cell Biol 112:955963.

Maher PA, Pasquale EB (1988) Tyrosine phosphorylated proteins in different tissues during chicken embryo development. J Cell Biol 106: 1747-1755.

Matten WT, Aubry M, West J, Maness PF (1990) Tubulin is phosphorylated at tyrosine by pp60 ${ }^{\text {c-src }}$ in nerve growth cone membranes. J Cell Biol 111:1959-1970.

Moos M, Tacke R, Scherer H, Teplow D, Fruh K, Schachner M (1988) Neural adhesion molcculc $L 1$ as a mcmbcr of the immunoglobulin superfamily with binding domains similar to fibronectin. Nature 334 : 701-703.

Moss AM, Unger JW, Moxley RT, Livingston JN (1990) Location of phosphotyrosine-containing proteins by immunocytochemistry in the rat forebrain corresponds to the distribution of the insulin receptor. Proc Natl Acad Sci USA 87:4453-4457.

Norton PA, Hynes RO, Rees JG (1990) sevenless: seven found? Cell $81: 15-16$.

O'Bryan JP, Frye RA, Cogswell PC, Neubauer A, Kitch B, Prokop C, Espinosa R, LeBeau MM, Earp HS, Liu ET (1991) axl, a transforming gene isolated from primary human myeloid leukemia cells, encodes a novel receptor tyrosine kinase. Mol Cell Biol 11:5016-5031.

Pang DT, Wang JKT, Valtorta F, Befenati F, Greengard P (1988) Protein-tyrosine phosphorylation in synaptic vesicles. Proc Natl Acad Sci USA 85:762-766.

Pasquale EB (1991) Identification of chicken embryo kinase 5, a developmentally regulated receptor-type tyrosine kinase of the Eph family. Cell Regul 2:523-534.

Pasquale EB, Singer SJ (1989) Identification of a developmentally regulated protein-tyrosine kinase by using anti-phosphotyrosine antibodies to screen a cDNA expression library. Proc Natl Acad Sci USA 86:5449-5453.

Ramon y Cajal S (1890) Sur les fibres nerveuses de la couche granuleuse du cervelet et sur l'evolution des elementes cerebelleux. Int Mtschr Anat Physiol 7:12-30.

Sajjadi FG, Pasquale EB, Subramani S (1991) Identification of a new eph-related receptor tyrosine kinase gene from mouse and chicken that is developmentally regulated and encodes at least two forms of the receptor. New Biologist 3:769-778. 
Sasahara M, Fries JWU, Raines EW, Gown AM, Westrum LE, Frosch MP, Bonthron DT, Ross R, Collins T (1991) PDGF B-chain in neurons of the central nervous system, posterior pituitary, and in a transgenic model. Cell 64:217-227.

Soppet D, Escandon E, Maragos J, Middlemas DS, Reid SW, Blair J, Burton LE, Stanton BR, Kaplan DR, Hunter T, Nikolics K, Parada LF (1991) The neurotrophic factors brain-derived neurotrophic factor and neurotrophin-3 are ligands for the trkB tyrosine kinase receptor. Cell 65:895-903.

Squinto SP, Stitt TN, Aldrich TH, Davis S, Bianco SM, Radziejewski C, Glass DJ, Masiakowski P, Furth ME, Valenzuela DM, DiStefano PS, Yancopoulos GD (1991) trkB encodes a functional receptor for brain-derived neurotrophic factor and neurotrophin-3 but not nerve growth factor. Cell 65:885-893.

Sudol M, Alvarez-Buylla A, Hanafusa H (1988) Differential developmental expression of cellular yes and cellular src proteins in cerebellum. Oncogene Res 2:345-355.

Sudol M, Kuo CF, Shigemitsu L, Alvarez-Buylla A (1989) Expression of the yes proto-oncogene in cerebellar Purkinje cells. Mol Cell Biol 9:4545-4549.

Tian S-S, Tsoulfas P, Zinn K (1991) Three receptor-linked proteintyrosine phosphatases are selectively expressed on central nervous system axons in the Drosophila embryo. Cell 67:675-685.
Tillotson ML, Wood JG (1989) Tyrosine phosphorylation in the postnatal rat brain: a developmental, immunohistochemical study. J Comp Neurol 282:133-141.

Wagner JA (1991) The fibroblast growth factors: an emerging family of neuronal growth factors. Curr Top Microbiol Immunol 165:95118.

Walicke P, Cowan WM, Ueno N, Baird A, Guillemin R (1986) Fibroblast growth factor promotes survival of dissociated hippocampal neurons and enhances neurite extension. Proc Natl Acad Sci USA 83:3012-3016.

Wanaka A, Johnson EM Jr, Milbrandt J (1990) Localization of FGF receptor mRNA in adult rat central nervous system by in situ hybridization. Neuron 5:267-281.

Wandosell F, Serrano L, Avila J (1987) Phosphorylation of $\alpha$-tubulin carboxyl-terminal tyrosine prevents its incorporation into microtubules. J Biol Chem 262:8268-8273.

Yang X, Seow KT, Bahri SM, Oon SH, Chia W (1991) Two Drosophila receptor-like tyrosine phosphatase genes are expresscd in a subset of developing axons and pioneer neurons in the embryonic CNS. Cell 67:661-673.

Yeh H-J, Ruit KG, Wang Y-X, Parks WC, Snider WD, Deuel TF (1991) PDGF A-chain gene is expressed by mammalian neurons during development and in maturity. Cell 64:209-216. 